\title{
NARRATIVA FANTÁSTICA: QUESTÃO DE LEITURA?
}

Karla Niels ${ }^{1}$

Resumo: A categorização do fantástico, como gênero, não tem sido inequívoca nos estudos literários. Para Tzvetan Todorov o fantástico surge como um efeito decorrente da ocorrência de acontecimentos estranhos e insólitos em meio à narrativa, bem como da possibilidade de se fornecer duas explicações para esses acontecimentos. Diante da ambiguidade expressa pelo insólito, "alguém" deve optar por uma saída: o personagem ou o próprio leitor (Cf. TODOROV, 2007). A identificação do leitor com o personagem, apesar de considerada por Todorov, é vista por ele como fator dispensável. A hesitação entre uma explicação e outra, sim, seria o ponto central para a concretização do gênero. Filipe Furtado (1980), por sua vez, não admite a intervenção de um leitor empírico nesse tipo de narrativa. A dúvida e a hesitação patentes ao gênero seriam somente da narrativa e não do leitor. Diante desse impasse, o trabalho visa considerar algumas teorias relacionadas ao leitor e à leitura, a fim de avaliar a pertinência de se admitir a hipótese da participação de um leitor real na construção das narrativas fantásticas e, em especial, naquelas em que o medo provocado no leitor pelos acontecimentos narrados constitui a sua força motriz (cf. ROAS, 2006).

Palavras-Chave: Fantástico, Leitura, Leitor, Recepção.

Resumen: La categorización de lo fantástico como género, no ha sido inequívoca en los estudios literarios. Tzvetan Todorov al efecto fantástico surge como resultado de la ocurrencia de eventos extraños e inusuales a través de la narrativa, así como la capacidad de ofrecer dos explicaciones para estos eventos. Dada la ambigüedad expresada por el inusual, "alguien" debe optar por una salida: el carácter o el lector de sí mismo (cf. Todorov 2007). Identificación del lector con el personaje, aunque considerado por Todorov, es visto por él como el factor prescindible. La vacilación entre una explicación y otra, sí, sería el punto central para la consecución de género. Filipe Furtado (1980), a su vez, no permite la intervención de un lector empírico de este tipo de narración de cuentos. La duda y la vacilación a la patente género serían sólo la narración y no el jugador. Ante este impasse, la obra apunta a considerar algunas teorías relacionadas con el lector y la lectura, con el fin de evaluar la conveniencia de admitir la hipótesis de la implicación de un jugador real en la construcción de fantásticos relatos y, en particular, aquellos en los que infli-

${ }^{1}$ Karla Menezes Lopes Niels; mestre em Literatura Brasileira pela Universidade do Rio de Janeiro (UERJ); tutora do consócio Cederj/UNIRIO, Faculdade de Pedagogia, Rio de Janeiro, Brasil; bolsista CAPES/UAB. Endereço eletrônico: Karla.niels@gmail.com. 
gen miedo el lector a través de los acontecimientos narrados es la fuerza impulsora (cf. ROAS, 2006).

Palabras-Clave: Fantástico, Lectura, Lector, Recepción.

\section{INTRODUÇÃO}

Fantástico, no senso comum, é aquilo que só existe num mundo de imaginação, muitas vezes relacionado ao extraordinário, ao prodigioso. Segundo o dicionário Caldas Aulete, no âmbito literário, trata-se de "modalidade de narrativa (romance, conto etc.) em que elementos sobrenaturais se misturam à realidade" (AULETE, 2009). Entretanto, a categorização do fantástico, como gênero, não tem sido inequívoca nos estudos literários.

Para Tzvetan Todorov, o fantástico surge como um efeito decorrente da existência de acontecimentos incomuns, sinistros ou insólitos, bem como da possibilidade de se fornecer duas explicações - natural ou sobrenatural - para esses acontecimentos. A hesitação entre uma explicação e outraseria o ponto central para a concretização do gênero.A essência do gênero na narrativa ficcional seria um efeito decorrente de "[...] um acontecimento que não pode ser explicado pelas leis deste mesmo mundo familiar" (TODOROV, 2007, p.30).

O fantástico surge, portanto,como efeito advindo da narração de um fenômeno aparentemente sobrenatural que se mantém no eixo de relação entre o real e o imaginário, entre o sólito e o insólito. Noutras palavras, o gênero depende da hesitação entre uma explicação natural e uma sobrenatural para dado fenômeno. A opção por uma das duas soluções coloca-nos diante de gêneros vizinhos ao fantástico - o estranho e o maravilhoso. 0 conceito do gênero parece definir-se então "com relação aos de real e de imaginário" (Id., p. 31); ou se aceita o acontecimento como pertencente à realidade ou como fruto do imaginário.

Diante do sobrenatural e do impossíveltanto personagem como leitor questionam-se sobre até que ponto aquilo é real ou imaginário, natural ou sobrenatural, sólito ou insólito. Mas a quem cabe a decidir sobre a natureza do fenômeno?

Aquele que o percebe [o acontecimento sobrenatural] deve optar por uma das duas soluções possíveis; ou se trata de uma ilusão dos sentidos, de um produto da imaginação e nesse caso as leis do mundo continuam a ser o que são; ou então o acontecimento realmente ocorreu, é parte integrante da 
realidade, mas nesse caso esta realidade é regida por leis desconhecidas para nós (Id, p. 30).

Todorov salienta que "alguém" (Id, p. 32) deve optar por uma saída: o personagem ou o próprio leitor. Foquemos no leitor. O leitor, ao se identificar com o personagem e se integrar à narração, preenche os "vazios" (cf. Iser, 1996) da narrativa e opta por uma solução para a ambiguidade ali presente, definindo a natureza do texto que lê; se fantástico, estranho ou maravilhoso.

Ressalte-se, no entanto, que a identificação empática do leitor com o personagem, apesar de considerada frequente por Todorov, é vista por ele como um aspecto contingente. A hesitação, sim, seria o ponto central para a concretização do gênero, desde que aambiguidade se mantenha até o final da narrativa, sem que se clarifique a natureza do fenômeno insólito. Quando produzida somente "durante uma parte da leitura", o que se tem é apenas um "efeito fantástico" (TODOROV, 2007, p. 48), e não a configuração completa do gênero.

Apesar da clara orientação estruturalista do ensaio de Todorov, apresenta lacunas que nos permitem vislumbrar a possível intervenção de um leitor empírico - aquele que se identifica com o personagem - num texto de características fantásticas, mesmo que aparentemente argumente a favor de um leitor ideal - aquele que, em termos formalistas, é arquitetado pelo texto, e cuja estrutura é muito próxima à de um narratário.

Filipe Furtado, estudioso contemporâneo do gênero, por outro lado, não admite a intervenção de um leitor empírico nesse tipo de narrativa. A dúvida e a hesitação patentes ao gênero ocorreriam somente no plano da narrativa e não como decorrência de um efeito de leitura, segundo ele. $A$ incerteza diante dos acontecimentos, portanto, seria construída através das estruturas textuais características ao gênero:

Com efeito, fazer depender a classificação de qualquer texto apenas (ou sobretudo) da reação do leitor perante ele equivaleria a considerar todas as obras literárias em permanente flutuação entre vários gêneros, sem alguma vez se permitir fixarem-se definitivamente num deles (FURTADO, 1980, p. 77).

Diante desse impasse, é possível considerar algumas teorias relacionadas ao leitor e à leitura, a fim de avaliar a pertinência de se admitir a hipótese da participação de um leitor real na construção das narrativas fantásticas. 
Por exemplo, desde a edição portuguesa de 1878 e da edição brasileira 1902 de Noite na taverna, de Manuel Antônio Álvares de Azevedo, em que figurava o subtítulo "Contos phantasticos", inúmeros foram os estudos que oscilaram em classificar os contos de Álvares de Azevedo ora como de cunho fantástico, ora como romance gótico.

Quando consideramos Noite na taverna a partir das premissas todorovianas, observamos que a obra de Azevedo privilegia o que o ensaísta considera como sendo o gênero estranho. Verdade, sonho ou alucinação, as narrativas não apresentam quaisquer acontecimentos inexplicáveis, e os poucos que aparecem são facilmente naturalizados ao fim. Entretanto, se admitirmos a participação do leitor na construção da narrativa, alguns de seus contos poderiam ser considerados como de cunho fantástico.

Um exemplo digno de nota é o quarto conto. Nele,Gennaro relata aos convivas da taverna como engravidara a filha do seu senhorio e mestre, Godofredo Walsh. Ao se ver grávida, desamparada e não correspondida pelo rapaz, a menina provoca um aborto e adoece gravemente. Após o falecimento da moça, seu pai é levado à loucura com a traição de Gennaro e de sua esposa Nauza. No momento em que a louca sede de vingança de Godofredo é extrema, o narrador dirá ter sentido calafrios que o fizeram confessar sua culpa ao seu algoz:

[...] um tremor, um calafrio se apoderou de mim [dele, o narrador]. Ajoelheime, e chorei lágrimas ardentes. Confessei tudo: parecia-meque era ela que o mandava, que era Laura que se erguia de entre os lençóis de seu leito, e me acendia o remorso, e no remorso me rasgava o peito (AZEVEDO, 2000, p. 585).

Como vemos, há apenas uma sugestão do sobrenatural, ao se insinuar a influência de Laura sobre seu pai após seu falecimento, quando o protagonista diz que parecia "que era ela que o mandava, que era Laura que se erguia de entre os lençóis de seu leito"para Ihe acender o remorso (Ibid., p.585). Ainda, é possível que o leitor subentenda que o tremor e os calafrios sentidos por Gennaro como sinais da presença de Laura, induzindo-o também à confissão. Uma vez que a sugestão não se aprofunda ao longo da narrativa, o "vazio" deixado neste trecho pede a intervenção imaginativa do leitor.

O italiano Remo Ceserani considera o envolvimento do leitor como parte dos procedimentos narrativos da literatura fantástica, mas sem abrir mão da surpresa e da hesitação diante da ambiguidade produzida pelo fe- 
nômeno insólito. Para ele a estrutura narrativa do conto fantástico tem por objetivo envolver fortemente o leitor, conduzindo-o

para dentro de um mundo a ele familiar, aceitável, pacífico, para depois fazer disparar os mecanismos da surpresa, da desorientação, do medo: possivelmente um medo percebido fisicamente, como ocorre em textos pertencentes a outros gêneros e modalidades, que são exclusivamente programados para suscitar no leitor longos arrepios na espinha, contrações, suores (CESERANI, 2004, p. 71).

O que já havia sidoressaltado pelo ficcionista e ensaísta H. P. Lovecraftao dizer que "atmosfera é a coisa mais importante, pois o critério final de autenticidade não é a harmonização de um enredo, mas a criação de uma determinada reação" (LOVECRAFT, 2007, p. 17) no público leitor. É claro que o americano referia-se à literatura de horror, mas cabe lembrar que a narrativa fantástica, assim como a narrativa de horror, nasce das lúgubres sementes plantadas pelo romantismo gótico - a morbidez, o horror melancólico, o sobrenatural e, a capacidade de provocar, através dos acontecimentos narrados, sentimentos e emoções peculiares no leitor, em especial o medo.

Enquanto a narrativa de horror mobiliza o leitor através do suspense, do susto e do pavor; as narrativas fantásticas, por seu turno, mobilizam seus leitores através da incerteza, do questionamento da realidade e da veracidade daquilo que o homem conhece do mundo que o cerceia (cf. ROAS, 2006).

O leitor de um texto fantástico,portanto, precisa envolver-se na narrativa, identificar-se com o personagem e reagir ao que lê. Isso explica o porquê de as narrativas que lidam com o sobrenatural, com o insólito, com o impossível e com o inexplicável fazerem tanto sucesso entre os diversos públicos leitores desde o século XIX, quando do surgimento da narrativa fantástica.

É como se esse tipo de ficção se prestasse"como um ensaio para a nossa própria morte" (KING, 1978, p. 17). O medo e a inquietude instigados pela narrativa é assim visto como um fator de educação sentimental: o leitor entende a sua vulnerabilidade através da vulnerabilidade do personagem, e com ele se identifica. Por que as narrativas que lidam com, medo e sobrenaturalidade atraem as pessoas? A resposta estaria relacionada ao medo como um efeito de leitura, posto que,

[...] inventamos horrores para nos ajudar a suportar horrores verdadeiros.

Contando com a infinita criatividade do ser humano, nos apoderamos dos 
elementos mais polêmicos e destrutivos e tentamos transformá-los em ferramentas - para desmantelar estes mesmos elementos. O temo catarse é tão antigo quanto o drama na Grécia [...], mas, mesmo assim, ele tem seu uso [...] (KING, 2007, p. 24).

O horrores dafiç̧ão apresenta-nos uma resolução momentânea, que ameniza, por um curto tempo nossos horrores mais profundos, uma vez que podemos experimentar sensações de perigo sem que a fonte do medo represente um risco real. A força da narrativa fantástica residiria exatamente nesse sentimento de reintegração que poderia emanar de um gênero especializado em morte, medo e eventos sobrenaturais. Ao mesmo tempo o surgimento do improvável desestabilizaria nossas crenças, fazendo-nos duvidar da realidade e daquilo que conhecemos do mundo.

É justamente a experiência advinda desse sentimento o que impulsiona o processo catártico no ato de leitura. Entramos, portanto, no campo das emoções estéticas, pois a experimentação de tais sensações é capaz de produzir esse prazer peculiar que Aristóteles denominara catarse. 0 conceito aristotélico está relacionado à produção e à expurgação das emoções através da ficção, o que é de suma importância para a consideração dos efeitos de recepção. A esse respeito, convém lembrar que os temas trabaIhados pelo gênero têm gerado uma infinidade de narrativas que produzem esse efeito receptivo muito particular: o medo, sentimento comumente relacionado aos gêneros que se desdobraram do gótico do século XVIII: o fantástico romântico e as posteriores narrativas de horror. Entendamos tal efeito como equivalente "à resposta ou reação motivada pelo texto no leitor [que] pode significar igualmente o impacto causado no sistema estético ou histórico de um dado período" (ZILBERMAN, 1989, p. 104).

Para David Roas (2001, 2006), o fantástico depende efetivamente do leitor. Isso porque o acontecimento sobrenatural surge a partir do mundo real do leitor, pois o inexplicável pretende transtornar a realidade desse leitor, questionando as leis que organizam o mundo empírico. Relembrando Irene Bessiére, o espanhol reintera que o gênero funciona como um marco entre o sujeito e a realidade estabelecida sócio culturalmente e, que, por isso, sempre trabalha temas que se relacionam às crenças de determinada época. Os temas do XIX não são os mesmo do XX e, aqueles que perduraram são retrabalhados de forma a mobilizar o leitor do século posterior cujas o senso de real e imaginário, natural e sobrenatural mudaram. O fantástico, portanto, dependerá sempre do conhecimento de mundo do leitor, a época em que vive e, sobretudo, da ideia que tem do real. 
Como já considerado por Lovecraft e Ceserani, o mundo construído nos relatos fantásticos deve refletir a realidade do próprio leitor. É preciso que a ambientação da narrativa seja verossímilpara que, diante da inexplicabilidade do fenômeno narrado, o leitor se inquiete diante da possibilidade de desestabilização daquilo que conhece como realidade. E, por fim, hesite diante de duas possibilidades de explicação para o fenômeno narrado:

La irrupción de lo impossible en ese marco familiar [o mundo habitual do leitor] supone una transgresión del paradigma de lo real vigente en el mundo extratextual. Y, unido a ello, un inevitable efecto de inquietude ante la incapacidade de concebir la coexistência de lo posible y lo imposible (ROAS, 2008, p. 104) $)^{2}$.

Entretanto, cabe-nos perguntar: até onde vai a participação do leitor na construção da narrativa fantástica? É apenas um expectador que, movido pelas peripécias da narrativa, aguarda o momento catártico? Ou seria o grande co-autor da narrativa fantástica? Poderia o envolvimento do leitor suplantar as estruturas narrativas e as modalizações da linguagem apresentadas pelo texto?

\section{LEITOR E LEITURA}

Os estudos literários do século XIX deram demasiada ênfase aos elementos autor e contexto. Outros, no século XX - a estilística, o formalismo, o new critcism e o estruturalismo - , tornaram autônoma a obra de arte, enfatizando a chamada "morte do autor" e valorizando demasiadamente a materialidade do texto.

Foucault (1992), no ensaio"O que é um autor", comenta que, historicamente, os textos passaram a ter autores na medida em que os discursos se tornaram transgressões com origens passíveis de punições. Pois, na Antiguidade, o anonimato não constituía nenhum problema. Heidegger (1992), entretanto, na introdução do ensaio"A origem da obra de arte", diz que nenhum dos dois se sustenta sozinho, referindo-se ao artista e à obra.

Barthes (1977), no ensaio "A morte do autor", enfatiza a questão da não existência do autor fora ou anterior à linguagem. Procurando apresen-

2 A irrupção do impossível em um quadro familiar [o mundo habitual do leitor] implica uma transgressão do paradigma vigente real no mundo extratextual. E ligado a ele, um efeito inevitável de inquietude diante da incapacidade de conceber a coexistência do possível edo impossível (ROAS, 2008, p. 104) - todas as traduções a seguir são minhas. 
tar a ideia do autor como sujeito social e historicamente constituído, o vê como um produto do ato de escrever. Para ele um escritor será sempre o imitador de um gesto ou de uma palavra anteriores a ele, mas nunca originais, sendo seu único poder mesclar e sobrepor escritas. Barthes retira a ênfase de um sujeito onisciente e produtor da linguagem para libertar a escrita do despotismo da obra, a saber, o livro. Em outras palavras, para o ensaísta, a morte do autor é o nascimento do leitor.

Inseridos nesse contexto de valorização da livre interpretação, muitas teorias foram articuladas visando às questões receptivas da obra literária, tais como a estética da recepção de Jauss ou a teoria do efeito estético de Wolfgang Iser, e estudiosos como Barthes colocaram sobre o leitor o papel fundamental da(re)construção do sentido do texto. Entretanto,

[...] as posições de Jauss e Iser não são, nem nunca foram, totalmente homólogas. Ao passo que Jauss está interessado na recepção da obra, na maneira como ela é (ou deveria ser) recebida, Iser concentra-se no efeito (Wirkung) que causa, o que vale dizer, na ponte que se estabelece entre um texto possuidor de tais propriedades - o texto literário, com sua ênfase nos vazios, dotado pois de um horizonte aberto - e o leitor (LIMA, 1979, p. 25).

Para Sartre, por outro lado, o leitor será sempre co-autor do texto que lê. O texto, sem o movimento de leitura de um leitor real, não passaria de rabiscos num papel, pois "ler implica prever, esperar, prever o fim da frase, a frase seguinte, a outra página [...]" (SARTRE, 1989, p. 35), num processo contínuo de co-produção autor-leitor.

Uma das premissas teóricas de Iser reafirma esse aspecto fenomenológico da leitura, com o conceito de "leitor implícito", leitor que só existe na medida em que o texto determina a sua existência através das estruturas imanentes. Apesar de não ter existência real, pressupõe uma leitura real:

As perspectivas do texto visam certamente a um ponto comum de referências e assumem assim o caráter de instruções; o ponto comum de referências, no entanto, não é dado enquanto tal e deve por isso ser imaginado. É nesse ponto que o papel do leitor, delineado na estrutura do texto, ganha seu caráter efetivo [...]. O sentido do texto é apenas imaginável, pois ele não é dado explicitamente[...] (ISER, 1996, p. 75).

Assim como Sartre, Iser admite a participação do leitor na (re)construção do sentido da obra através da leitura como ato estruturado.

Saindo de uma tradição estruturalista e partindo para uma visão semiótico-pragmática, Umberto Eco publica, em 1961,Obra Aberta,um estudo de estética que tocava nas questões receptivas e interpretativas de uma 
obra literária. $O$ ensaio abordou a dialética entre a problemática da liberdade de interpretação e a fidelidade ao texto, propondo um modelo teórico que visa não negar o autor como fez o estruturalismo, mas consciente de que o empirismo do leitor pode ser um potencial causador de problemas interpretativos. A propósito disso, é válido citarmos o comentário de Sandra Cavicchioli:

questa dialettica si è manifestata nel coniugare la tradizione dello struturalismo e quella del pragmatismo de Peirce, con l'obiettivo di non chiudere troppo il testo su se stesso e al contempo non aprirlo illimitatamente a ogni tipo di istanza interpretativa (ECO, 1995, p. 184) ${ }^{3}$.

Para Eco, todo texto literário é uma "machina pigra"4 (ECO, 1994, p. 3) que sobrevive da valorização do sentido que o leitor ali introduz, contando sempre com o conhecimento de seus leitores para atualizá-lo. Por ser "pigra", toda narrativa é muito lacunar e, quanto mais lacunar for, maiores serão os riscos de interpretações absurdas, como parece ocorrer em romances de cunho pisicológico. Por exemplo, o romance epistolar Va dove ti porta il cure, de Suzanna Tamaro, conduz a uma leitura reflexiva sobre a condição humana, reflexão que pode levar o leitor a abandonar a materialidade do texto para adequá-lo aos seus ideais políticos, sociais ou psicológicos, uma condição não ideal de leitura. Do mesmo modo, poder-se-ia ler $O$ processo, de Kafka, como um romance policial, o que é viável, mas, textualmente, não surtiria bons efeitos.

Outro exemplo desse movimento, de participação do leitor na construção da narrativa, visto sob um prisma positivo, são as narrativas de vanguarda, que, ao contrário das tradicionais, não procuram identificar e instruir seu leitor, mas são construídas de modo a frustrá-lo e surpreendê-lo, exigindo dele um trabalho maior no processo interpretativo. Preencher tais lacunas, ou "vazios", se usarmos o termo de Iser, portanto, não significa construir outro texto diverso do inicial, mas aceitar o jogo proposto. Entretanto, tal afirmação reitera o pressuposto de que o texto precisa de um leitor para concretizá-lo.

Nesse sentido, o leitor é condição indispensável para a capacidade concreta da comunicação do texto e da sua potencialidade criativa:

\footnotetext{
${ }^{3}$ Esta dialética se manifestou na combinação da tradição do estruturalismo e do pragmatismo de Peirce, com o objetivo de não fechar demais o texto sobre si mesmo e ao mesmo tempo não abri-lo ilimitadamente a cada tipo de instância interpretativa (ECO, 1995, p. 184).
}

4 Máquina pobre (ECO, 1994, p. 3). 
In un testo narrativo il lettore è costretto a ogni momento a compiere una scelta. Anzi, quest'obbligo della scelta si manifesta persino a livello di qualsiasi enunciato, almeno a ogni occorrenza di un verbo transitivo. Mentre il parlante si accinge a terminare la frase noi, sai pure inconsciamente, facciamo una scommessa, anticipiamo la sua scelta, o ci chiediamo angostiati quale scelta farà [...] (ECO, 1994, p. 7) $)^{5}$.

O leitor empírico, ao contrário do leitor modelo, não é compromissado com o texto, e por isso o usaa seu bel-prazer, produzindo os mais diversos sentidos. O leitor modelo não é um leitor de carne e osso, como todos nós que lemos e fazemos as mais diversas suposições sobre a obra; é na verdade uma criação do próprio texto, efeito de suas estruturas narrativas.

Para Eco, trata-se, portanto, de "un lettore-tipo che il testo non solo prevede come collaboradore, ma anche cerca di creare $^{\prime 6}$ (ECO, 1994, p. 11). Em outras palavras, o leitor modelo é aquele que pergunta: como é que esse texto precisa ser lido? E a resposta a essa pergunta está justamente no autor modelo, ou seja, na observação atenta das estratégias narrativas e das marcas próprias do gênero.

O ensaísta diz, ainda, que seu leitor modelo é muito similar ao leitor implícito de Wolfgang Iser. No entanto, mesmo que inicialmente Iser coloque o leitor implícito como estrutura textual imanente ao texto, admite uma leitura real, como ato estruturado, fora do texto. Paola Pugliatti, ao comentar Iser, afirma que o ensaísta "assengna al lettore un privilegio che è stato considerato prerrogativa dei testi"7 (ECO, 1994, p. 20). Digamos, então, que, para Iser, o leitor condiciona o texto, enquanto para Eco o texto condiciona o leitor. Por isso, o alessandrino assinala que fixa a sua atenção no que Iser chamouleitor fictício retratado no texto, uma concepção bastante aproximada do leitor ideal todoroviano, o qual, em termos formalistas, é o leitor arquitetado pelo texto. Assim, é possível pensar toda leitura

5 Em um texto narrativo, o leitor é forçado a cada momento a fazer uma escolha. Além, esta obrigação de escolha se manifesta através do nível de qualquer enunciado, pelo menos a cada ocorrência de um verbo transitivo. Enquanto o falante está prestes a terminar a frase, nós, mesmo que inconscientemente, fazemos uma aposta, antecipamos a sua escolha, ou nos sentimos angustiados em querer saber qual escolha ele fará (ECO, 1994, p. 7).

6 Um leitor-tipo que o texto não somente prevê como colaborador, mas também procura criar (ECO, 1994, p. 11).

7 Atribui-se ao leitor um privilégio que foi considerado prerrogativa dos textos (ECO, 1994, p. 20). 
como um processo empírico, e a leitura modelo como uma idealização teórica.

\section{O LEITOR DE UM TEXTO FANTÁSTICO}

O texto literário, na sua generalidade, espelha a plasticidade humana, permitindo ao leitor visualizar aspectos e detalhes que assomam às palavras e configuram um quadro mental, imagético, pictórico, fruto do imaginário humano, pois "o que caracteriza a literatura é [justamente] a articulação organizada do fictício e do imaginário" (ISER, 1996, p. 8), em que o imaginário emerge da realidade repetida na ficção. Por isso, o texto apresenta lacunas que se deslocam por sua estrutura e provocam o deslocamento do ponto de vista do leitor, requerendo o preenchimento destas pelo sujeito, num ato de construção participativa dos sentidos ali expressos. Ciente disso, "o escritor apela à liberdade do leitor para que esta co- labore na produção da sua obra" (SARTRE, 1989, p. 39). Porém, trata-se de uma liberdade vigiada, pois preencher as lacunas não significa construir outro texto diferente do inicial. O leitor precisa respeitar as regras do jogo, conforme Eco,agarrando-se à estrutura do texto e às pistas que ali são deixadas.

O leitor de um texto fantástico vivencia os acontecimentos narrados, e, através das pistas que os modalizadores da linguagem - o emprego do verbo no imperfeito, o uso do modo no subjuntivo, os advérbios de dúvida, o ponto de interrogação e as reticências (que suspendem a informação e criam um "vazio" a ser preenchido) - e os topoi góticos lhe deixam, participa ativamente da construção da narrativa.

Voltemos ao exemplo do conto "Gennaro", de Álvares de Azevedo,dado acima. No conto, houve a sugestão do sobrenatural: a sobrevida após a morte de Laura e a sua influência sobre as atitudes assassinas de seu pai. Essa sugestão deu-se, principalmente, através da modalização da linguagem. O uso do verbo "parecer" no pretérito imperfeito do indicativo, em "parecia-me que era ela que o mandava, que era Laura que se erguia de entre os lençóis de seu leito" (AZEVEDO,2000, p.5 85 - grifo nosso), subentende um aspecto indutivo, e "introduz uma distância entre a personagem e o narrador" (TODOROV, 2007, p. 44), mesmo se tratando de um narrador-personagem. A modalização, portanto, propicia não só a sugestão do sobrenatural, mas também pede a intervenção de um leitor empírico que preencha a lacuna ali deixada. O verbo, portanto, introduz uma 
sugestão que não se aprofunda no decorrer do conto, fazendo-se necessário que o sujeito participe na construção do sentido daquilo que é sugerido.

Assim como postulado por Todorov e, principalmente, por Lovecraft e Ceserani, David Roas cola o leitor ao personagem:

El lector, como los personajes de la novela, es enfrentado a unos fenómenos cuya presencia excede toda capacidad de comprensión, y ante los cuales no cabe otra reacción que la sorpresa, la duda y el temor. Y así, todo aquello que representaban esos seres sobrenaturales (que podemos resumir en el miedo a la muerte ya lo desconocido) se trasladará al mundo de la ficción, para seguir aterrorizando al hombre. Peró éste ya no será un terror creído, sino un terror, como dije antes, gozado (ROAS, 2006, p. 62, 63).

Ao perceber a presença do sobrenatural, do improvável, o leitor vê o fenômeno como uma transgressão à sua experiência coletiva da realidade, ao seu horizonte de expectativas a respeito do real. Por isso,compartilha da hesitação e do medo do personagem e, quando não explicitado na narrativa, é ele, o leitor, quem decidirá que solução dar ao acontecimento aparentemente sobrenatural; é ele quem preencherá o "vazio" da dúvida, articulando seu presente, fazendo conexões relevantes com sua história, com aquilo que entende por real para, por fim, tomar uma decisão sobre o sentido do texto sua natureza.

Roas ainda argumenta que mesmo que narrador e personagem não se inquietem diante do acontecimento insólito, o leitor, envolvido com o universo narrativo, não deixa de fazê-lo, visto que se depara com fenômenos vão além de sua concepção do real (cf. ROAS, 2011).

Entretanto, esse leitor não goza de total liberdade ao construir o sentido da narrativa fantástica; é conduzido pelas estratégias narrativas do texto, pelos modalizadores da linguagem, e algumas vezes pelas leituras anteriores de textos do mesmo gênero que compõem o seu repertório (cf. ISER, 1996).

O processo de leitura de um texto fantástico, na verdade, é um processo circular, em que o leitor cria hipóteses a partir do seu horizonte de expectativas e do seu repertórioque devem ser confirmadas pelo texto,

${ }^{8} \mathrm{O}$ leitor, como os personagens do romance, se depara comum fenômeno cuja presença excede todo o poder de compreensão, e que não cabe outra reação que não adúvida, a surpresa e o medo. E assim, tudo o que representou esses seres sobrenaturais (que cair no medo da morte e do desconhecido) vai passar para omundo da ficção, para continuar aterrorizando o homem. Mas isso não é mais que umterror crido, mas um terror, como eu disse antes, gozado (ROAS, 2006, p. 62, 63).

Número temático: Vertentes do insólito nas literaturas das Américas. A Cor das Letras - 
cujas partes que estão sendo interpretadas precisam convergir com o próprio texto, mesmo que se estabeleça relações com o mundo extratextual do leitor. Embasamos tal hipótese em Umberto Eco:

La lettura delle opere letterarie ci obbliga ad un esercizio della fedeltà e del rispetto nella libertà dell'interpretazione. C'è una pericolosa eresia critica, tipica dei nostri giorni, per cui di un'opera letteraria si può fare quello che si vuole, leggendovi quanto i nostri più incontrollabili impulsi ci suggeriscono. Non è vero. Le opere letterarie ci invitano alla libertà dell'interpretazione, perchè ci propongono di fronte alle ambiguità e del linguagio dellavita. Ma per poter procedere inquesto gioco, per cui ogni generazione legge le opere letterarie in modo diverso, ocorre essere mossi da un profondo rispetto verso quella que io ho altrove chiamato l'intenzione del testo (ECO, 2002, p. $11)^{9}$

Ao dialogar com o universo do leitor, o fantásticosolicita seu envolvimento com o universo narrativo para (re)construir os sentidos ali expressos.O leitor, portanto, parte de seu conhecimento de mundo, horizonte de expectativas e repertório para preencher os "vazios"da narrativa. Teme e se inquieta quando o inexplicável surge, mas o texto não fica à mercê de suas idiossincrasias, pois serão as estrutura narrativa e a modalização da linguagem que o conduziram à decisão final.

\section{REFERÊNCIAS}

AZEVEDO, Álvares de, 1831-1852. Obra completa. Org. Alexei Bueno; textos críticos, Jaci Monteiro et al. Rio de Janeiro: Nova Aguilar, 2000.

BARTHES, Roland. The death of the author. In: Image, music, text. Essays selected and trans. Ed. by Stephen Heath. New York: Hill, 1977.

CESERANI, Remo. O fantástico. Trad. Nilton César Tridapalli. Curitiba: Ed. UFPR, 2006.

ECO, Umberto. Obra aberta. São Paulo: Perspectiva, 1976 [1961].

\footnotetext{
${ }^{9}$ A leitura das obras literárias nos obriga a um exercício de fidelidade e do respeito a liberdade de interpretação. Há uma perigosa heresia crítica, típica dos nossos dias, que de uma obra literária se pode fazer aquilo que se quer, lendo o que nossos mais incontroláveis impulsos nos sugerem. Não é verdade. As obras literárias nos convidam à liberdade de interpretação, porque nos propõem ficar diante das ambiguidades e da linguagem da vida. Mas, para poder proceder neste jogo, no qual cada geração lê as obras literárias de uma maneira diferente, ocorre ser movido por um profundo respeito por aquilo que através daquela que, em outro lugar, chamei de intenção do texto (ECO, 2002, p. 11).
} 
ECO, Umberto. Sei Passeggiate nei Boschi Narrativi. Milano: Tascabili Bompiani, 2007 [1994].

ECO, Umberto. Interpretazione e sovrainterpretazione. Milano: Tascabili Bompiani, 2004 [1995].

ECO, Umberto. Sulla Letteratura. Milano: Tascabili Bompiani, 2003 [2002].

FANTÁSTICO. In: AULETE digital: dicionário contemporâneo da língua portuguesa. Rio de Janeiro: Lexikon Ed. Digital, 2008. Disponível em: $<w w w$.auletedigital.com.br>.

FOUCAULT, Michel. O que é um autor? Trad. Antonio F. Cascais e Edmundo Cordeiro. Lisboa: Vega, 1992.

FURTADO, Filipe. A construção do fantástico na narrativa. Lisboa: Horizonte, 1980.

HEIDEGGER, Martin. A origem da obra de arte. Lisboa: Ed. 70, 1992.

ISER, Wolfgang. $O$ ato de leitura: uma teoria do efeito estético. Trad. Johannes Kretschmer. São Paulo: Ed. 34, 1996, v. 1.

ISER, Wolfgang. $O$ ato de leitura: uma teoria do efeito estético. Trad. Johannes Kretschmer. São Paulo: Ed. 34, 1996, v.2

ISER, Wolfgang. O fictício e o imaginário: Perspectivas de uma antropologia literária. Trad. Johannes Kretschemer. Rio de Janeiro: EdUERJ, 1996.

KING, Stephen. Dança macabra: o fenômeno do horror no cinema, na literatura e na televisão dissecado pelo mestre do gênero. Trad. Louisa Ibañez. Rio de Janeiro: Objetiva, 2003.

KING, Stephen. Sombras da noite. Trad. Luiz Horácio da Matta. Rio de Janeiro: Globo, 1978.

LIMA, Luiz da Costa. (Sel., coord. e trad.). A literatura e o leitor. Rio de Janeiro: Paz e Terra, 1979.

LOVECRAFT, Howard Phillips. O horror sobrenatural em literatura. Trad. Celso M. Paciornik. Apres. Oscar Cesarotto. São Paulo: lluminuras, 2007.

ROAS, David. El nacimento de lo fantástico. In: De la maravilla al horror: Los inicios delo fantástico en la cultura española (1750-1860). Pontevedra: Mirabel Editorial, 2006.

ROAS, David. Lo fantástico como desestabilización de lo real: elementos para una definición. In: Teresa López Pellisa y Fernando Ángel Moreno. (Ed.). Ensayos sobre literatura fantástica y ciencia ficción. Universidad Carlos III de Madrid, Madrid, 2009. Disponível em: http://earchi-

vo.uc3m.es/bitstream/handle/10016/8584/fantastico_roas_LITERATURA_20 08.pdf. Acesso em: 28 nov. 2013.

ROAS, David. Em torno a uma teoria sobre o medo e o fantástico. Trad. Lara D'Onofrio Longo. In: VOLUBUEF, Karin; WIMMER, Norma; HERRERA, Roxana 
Guadalupe. (Org.).Vertentes do fantástico na literatura. São Paulo: Annalube, 2011.

SARTE, Jean-Paul. Que é a literatura? Trad. Carlos Felipe Moisés. São Paulo: Ática, 1989. [1948].

TODOROV, Tzvetan. Estruturalismo e poética. São Paulo: Cultrix, s/d [1968].

TODOROV, Tzvetan. Introdução à literatura fantástica. Trad. Maria Clara Correa Castello. São Paulo: Pespectiva, 2007.

ZILBERMAN, Regina. Estética da recepção e história da literatura. São Paulo: Ática, 1989. 